\title{
Minimalism and Truth Aptness
}

Frank Jackson, Michael Smith and Graham Oppy

Non-cognitivism in ethics holds that ethical sentences are not in the business of being either true or false - for short, they are not truth apt. No-truth theories of indicative conditionals (on one labelling of the relevant class of conditionals) hold that indicative conditionals have assertability or acceptability conditions, but not truth conditions; they are not truth apt. The arguments for these views are typically local to ethics and conditionals, respectively. They are not usually set within a specific theory of truth, and the question of how they connect to the various theories of truth is typically left unaddressed. This is surprising. ${ }^{1} \mathrm{An}$ obvious question to ask about non-cognitivism and no-truth theories of conditionals is how they fare in the light of various views about truth.

This paper is concerned with an increasingly popular position on the obvious question. According to this position, a certain view about truth, often called 'minimalism about truth', leads pretty well immediately, and in any case without recourse to the considerations distinctive of the debates in the ethics' and conditionals' literatures, to the conclusion that ethical sentences and indicative conditionals are truth apt. A variant on this position distinguishes kinds of truth, and holds that thin truth, or disquotational truth, or at any rate some core, non-robust notion of truth, cannot sensibly be denied to ethical sentences and conditionals, and that, accordingly, the live issue should be

1 As Paul Boghossian in 'The Status of Content', Philosophical Review, XCIX, 1990, pp. 157 - 184, notes, A. J. Ayer in Language, Truth and Logic, Gollancz, 1936, simultaneously defends a 'no real property' account of truth and the view that ethical sentences are neither true nor false, without addressing the question of the possible tension between these two positions. 
thought of as whether, on some thick or robust notion of truth - perhaps tied to correspondence with reality in some metaphysically heavyweight sense, or to mind independence, or to evidence transcendence, or ... - ethical sentences and conditionals are truth apt. 2 In this paper, we argue that this is a mistake. The distinctive considerations cannot be side-stepped.

As the argumentation to come is, of necessity, somewhat complex, it may help to have a map. In section one we characterise minimalism about truth and argue that the usual arguments from minimalism about truth to the falsity of non-cognitivism and no-truth theories of conditionals fail, and that only an appropriate minimalism about truth aptness could yield the sought for refutation of non-cognitivism and no-truth theories. In sections two and three we discuss two appropriately minimal accounts of truth aptness - syntacticism and disciplined syntacticism - and argue that they fail. In section three we defend a general condition on any acceptable account of truth aptness, a condition that

2 These views, in one or another form, appear in Boghossian, op. cit.; Crispin Wright, Truth and Objectivity, Harvard University Press,1992; Paul Horwich, 'Gibbard's Theory of Norms', Philosophy and Public Affairs, 1993, pp. 67 - 78; and I. L. Humberstone, Critical Notice of F. Jackson, Conditionals, Philosophy and Phenomenological Research, LI, 1991, pp. 227 - 234. There are important differences between these authors. Boghossian argues that if minimalism about truth is correct, truth aptness is easy to achieve. Wright and Humberstone commit themselves to kinds of truth and hold that for minimal (kinds of) truth, it must be allowed that ethical sentences (and conditionals in Humberstone's case) are truth apt independently of the distinctive considerations in the ethics and conditionals literature. Horwich's position is the most straightforward: there is one, minimalist notion of truth, and we can see that ethical sentences and conditionals are apt for its possession independently of the distinctive considerations. 
means that no (correct) account of truth aptness can be appropriately minimal, and indeed, as we argue in section four, this general condition vindicates the relevance of the kinds of considerations distinctive of the debates in the ethics' and conditionals' literatures. The attempt to short-circuit them by appeal to minimalism about truth or minimalism about truth aptness is a mistake. The final section notes a moral for minimalism about truth arising from the discussion earlier of minimalism about truth aptness.

Most of what we say applies equally to non-cognitivism in ethics and to no-truth theories of conditionals. Accordingly, the discussion will usually be developed for the case of ethics alone, and often in terms of the one example, the question of the truth aptness of 'Torture is wrong'.

\section{Minimalism about truth and minimalism about truth aptness}

Minimalism about truth is characterised in various ways by various authors, and not always under the banner of minimalism. Sometimes the emphasis is on the role of the truth predicate as a device of disquotation - the fact that attaching 'is true' to a sentence flanked by quotation marks yields something equivalent to the flanked sentences. Sometimes the emphasis is on the redundancy of talk about truth - the fact that the truth predicate and sentential prefixes like 'It is true that' and 'It is the case that' are systematically eliminable. Sometimes, the emphasis is on the deflationary nature of truth. One who understands 'Snow is white' knows what it takes for 'Snow is white' to be true, namely, snow's being white; and likewise knows what it takes for something Fred says to be true, namely, snow's being white and Fred's saying it, or grass's being green and Fred's saying it, and so on. There is no such subject as the nature of truth as such; rather, there are only such subjects as the nature of snow, and the question of why it is white. 
For present purposes this rough characterisation will serve. The points we want to make about truth aptness can be made without going into a detailed discussion of the connections between the various elements of the minimalist conception of truth. We will, however, note at the end a moral for minimalism about truth arising from our discussion of truth aptness.

How might minimalism about truth - understood in terms of one or another of these three doctrines, or some near relative - be thought to lead pretty well directly to the falsity of non-cognitivism and of no-truth theories of conditionals? Non-cognitivism says that 'Torture is wrong' is like 'Ugh' and 'Hooray, hooray' in being among the non-truth-apt linguistic items whose proper use we learn when we learn English. Similarly, no-truth theories of conditionals offer accounts of how conditionals get to be meaningful linguistic items in virtue of having well-defined acceptability conditions, where these conditions are explained without having to suppose that the acceptability in question is acceptability as true; indeed, typically a proof is offered to show that the acceptability they possess cannot be acceptability as true. It is hard to see straight-off how minimalism about truth per se could undermine such positions on truth aptness.

The answer favoured by Horwich is that minimalism about truth means that the appropriate substitutions in the T-schema:

(T) 'p' is true iff $p$

deliver truth conditions (or, on the variant position favoured by Humberstone, truth conditions in some sense: the thin or disquotational or deflationary sense) for ethical sentences and conditionals. 3 Thus, substituting in T, we might get:

3 Humberstone, op. cit., p. 231; Horwich, 'Gibbard's Theory of Norms', op. cit., pp. $73-4$. 
(1) 'Torture is wrong' is true iff torture is wrong.

and so, runs the argument, 'Torture is wrong' has a truth condition, and is thereby truth apt.

There is an obvious problem with this argument. Granted, if (1) gave the condition under which 'Torture is wrong' is true, it would follow that 'Torture is wrong' is truth apt. But (1) only does that if its right-hand side is truth apt, and that is the question. The argument, as it stands, is as unconvincing as arguing that 'P and Q' differs in truth conditions (or in thin truth conditions) from 'P but Q' by appeal to:

(2) 'P but $Q$ ' is true iff $P$ but $Q$.

and

(3) ' $\mathrm{P}$ and $\mathrm{Q}$ ' is true iff $\mathrm{P}$ and $\mathrm{Q} .4$

Granted, the right-hand sides are different, but the issue is whether they are different in truth conditions. In the case of (1) the issue is whether the righthand side has truth conditions. Just as the mere difference in what appears on the right-hand sides of (2) and (3) does not show a difference in truthconditions, the mere existence of a right-hand side in (1) does not show the existence of a truth condition. Non-cognitivists deny that the right-hand side of (1) specifies the conditions under which the sentence 'Torture is wrong' is true because they deny that the sentence which is the right-hand side of (1) is truth apt. In other words, they deny that that instance of $(T)$ is itself true. Of course, they accept (1) in some sense of 'accept', namely, the sense in which they

\footnotetext{
4 But see Humberstone, op. cit., p.231, for a version of this argument.
} 
accept that torture is wrong. But they do not and cannot accept it in the sense of accepting it as true. The essential point can be put this way: the fact that one way of giving the truth conditions of a truth apt sentence is to write down the sentence itself does not per se tell us anything about which sentences are truth apt. (Matters would be quite different, of course, if we were talking about propositions rather than sentences, for propositions are by definition truth apt. The issue is whether ethical and conditional sentences express propositions.)

There are, therefore, two quite separate questions. One is whether truth is, in some sense, minimal. The other is whether, as some minimalists about truth also hold, truth aptness is, in some sense, minimal. 5 Prima facie there are two distinct questions here: one is what makes for truth among the truth apt, what divides the true from the false among the items that are apt for truth and falsity; the other is what makes for truth aptness among the whole range of linguistic items, only some of which are truth apt. Indeed, as we will see later, the issue of truth aptness raises quite distinctive questions of its own.

Might there be some other argument from minimalism about truth to the falsity of non-cognitivism and no-truth theories of indicative conditionals? Sometimes the emphasis in the argument from minimalism to the falsity of noncognitivism and no-truth theories (or to their falsity when understood in terms of a thin notion of truth) is not so much on the role of the T schema in giving truth conditions, but rather on the minimalist's view that the truth predicate is a device of semantic ascent, and sometimes it is on the fact that we understand ethical sentences and conditionals, in the sense that they are significant. 6 But it

5 See, e. g., Paul Horwich, 'The Essence of Expressivism', Analysis, forthcoming.

6 Both are prominent themes in Paul Boghossian's discussion in 'The Status of Content', Philosophical Review, XCIX, 1990, pp. 157 - 184, see esp. pp.161 167. 
is hard to see the relevance of either to whether minimalism about truth entails that 'Torture is wrong' or 'If it rains, the match will be cancelled' is truth apt.

The truth predicate can serve as a device for switching from talk of reality to talk of sentences, as W. V. Quine spells out in many places. ${ }^{7}$ Instead of discussing the whiteness of snow, we can discuss the truth of 'Snow is white'. As Michael Devitt puts it: 'On the deflationary view, truth and falsity terms are linguistic devices for talking about reality by referring to sentences.' 8 But none of this means that any old sentence can be used as a device for talking about reality by appending the truth predicate. It means that some sentences can be so used, and the non-cognitivist insists, of course, that 'Torture is wrong' is not among the ones that can, any more than 'Hullo, hullo' is. Of course, if 'Torture is wrong' and 'If it rains, the match will be cancelled' make claims about reality, then appending 'is true' to them will be a device for talking about reality via talk of truth of sentences; but non-cognitivists and no-truth theorists precisely deny that such sentences do make claims about reality.

Likewise, it is hard to see the relevance of the fact that ethical sentences and conditionals are significant in the sense of being understood and having meanings that need to be learnt. 'Hullo, hullo' and 'Close the door' are both significant in that sense, and yet (on most views) neither is truth apt - indeed, it is because we understand them that we know that they are not truth apt. Someone who did not know the meaning of either would have to be agnostic about whether or not they were truth apt.

We thus conclude that minimalism about truth in itself poses no threat to non-cognitivists in ethics and no-truth theorists of indicative conditionals. Only

7 Paul Boghossian refers to the discussion in W. V. Quine, The Philosophy of Logic, Prentice-Hall, 1970, pp. 11 - 12.

8 Michael Devitt, 'Transcendentalism about Content', Pacific Philosophical Quarterly 71, 1990, pp. 247 - 263, p. 253. 
an independent, appropriately minimalist theory of truth aptness would pose a genuine threat - a theory that somehow made it 'easy' to be truth apt, and in any case sufficiently easy to ensure that ethical sentences and conditionals come out as truth apt automatically. Two such theories are syntacticism and disciplined syntacticism. We will argue that neither is satisfactory.

\section{Syntacticism}

According to syntacticism, truth aptness is purely and simply a matter of syntax. To be truth apt is simply to belong to the syntactically demarcated category of declarative sentences. Provided the sentence can be significantly embedded in suitable constructions - for example, negation, conditional, propositional attitude and truth ascriptions - then, according to the syntacticist, that sentence is truth apt. Although at places Wright and Boghossian express some sympathy for syntacticism (as an account of aptness for minimal truth), it is clear that their considered view is disciplined syntacticism discussed below. Our reason for discussing syntacticism is that it is important to have before us precisely what is wrong with it. 9

Syntacticism entails that ethical sentences and conditionals are truth apt. For 'Torture is wrong' certainly has the syntax syntacticism makes constitutive of being truth apt: it can be embedded in negation contexts ('It is not the case

9 But note that syntacticism is the theory Daniel Stoljar, 'Emotivism and Truth Conditions', Philosophical Studies, 70, 1993, pp. 81 - 101, calls the deflationary conception of possessing truth conditions, and under that name is ascribed by him to both Ayer and Horwich, Truth, Basil Blackwell, 1990. However, it is unclear that they are syntacticists in view of the fact that they insist their view of truth is a view of truth for propositions, that is, for entities that by definition do not raise the question of truth aptness. 
that torture is wrong'), conditional contexts ('If torture is wrong then we will make it illegal'), propositional attitude contexts ('I wonder whether torture is wrong'), truth ascription contexts ('“Torture is wrong" is true') and so on. And the same goes, of course, for 'If it rains, the match will be cancelled'.

There is, however, an obvious argument against syntacticism. In order to establish a background for this argument we ask the following question. What determines that a truth apt sentence has the particular truth conditions that it does?

The precise answer to this question is a notoriously difficult matter, but this much is clear. It is neither necessary nor a priori that a sentence, say, the sentence 'There is a cup on the desk', has the truth conditions that it does. And, moreover, prominent among the contingent and a posteriori matters that help determine what its truth conditions are, are complex facts about patterns of word and sentence usage. 10 For instance, had the word 'cup' been used in the way 'mug' is in fact used, and vice versa, then 'There is a cup on the desk' would have had the truth conditions that 'There is a mug on the desk' actually has, and vice versa. Hence, the truth conditions of 'There is a cup on the desk' depend inter alia on the contingent and a posteriori facts about the circumstances in which the word 'cup' is used.

Or consider the naming of currency. The Australian dollar was originally going to be called the 'royal'. If there had not been an outcry about the name then the sentence 'The royal fell against sterling during 1992' would, first, have had a truth condition (which in fact it does not); second, have been true most likely (it is hard to see how the difference in name would have helped); and

10 See, e. g., David Lewis, Convention, Harvard University Press, 1969. Each sentence and word token, of course, appears once and once only. We need thus to think of the sentence and word types as having patterns of usage in virtue of facts, actual and hypothetical, about their tokens. 
third, have had the truth conditions 'The Australian dollar fell against sterling during 1992' in fact has.

On some conceptions of what minimalism amounts to, the minimalist denies that whether or not a sentence is true, or has one set of truth conditions rather than another, depends in any way on facts about its usage. For example, Hartry Field suggests that deflationary truth is a property that 'a sentence has or fails to have independently of the way that the sentence is used by speakers'. 11 However, to make this part of minimalism is, it seems to us, to make the doctrine very implausible. As Field notes, it means that there is no difference between "if we had used the word "white" differently, "grass is white" might have been true' and 'if we had used the word "white" differently, grass might have been white'. He does not see this as an objection. We do. Moreover, the doctrine is not minimalism as understood by Wright and Boghossian. For then there would be no role for discipline to play in securing truth aptness; they would have to be syntacticists and not disciplined syntacticists. Discipline, as we will see, is a matter of there being clear occasions for using and not using a sentence, and it could hardly be necessary for a sentence to have such clear occasions in order to be truth apt if their nature had nothing to do with the conditions under which the sentence is true. We will see, though, in the appendix, that the point about usage means that one understanding of what minimalism about truth amounts has to be rejected if the view is to be plausible. 12

11 Hartry Field, 'The Deflationary Conception of Truth' in Graham Macdonald and Crispin Wright, eds, Fact, Science and Morality, Basil Blackwell, 1986, see p. 58.

12 We are here, of course, thinking of sentences as physical types, as is Field. There is a usage of 'sentence' to mean semantically individuated items. The question we are addressing, however, is how certain physical structures get to 
The second piece of background we need is the point that to be truth apt is for there to be truth conditions that are had. For in the sense at issue, to be truth apt is to have truth conditions. A sentence that has truth conditions must have some particular truth conditions. Granted, the truth conditions may be to some extent indeterminate, but they cannot be totally indeterminate.

We can now give our argument against syntacticism:

(a) Enough by way of syntactical facts alone is sufficient for being truth apt. (For reductio)

(b) It is impossible for a sentence to be truth apt without there being truth conditions it has. (Conceptual truth noted in second piece of background)

(c) Enough by way of syntactical facts alone is sufficient for having one set of truth conditions rather than another. (From (a), (b))

(d) A necessary condition for having one set of truth conditions rather than another is having a rich enough pattern of usage to determine truth conditions. (From first piece of background)

(e) Enough by way of syntactical facts is sufficient for having a rich enough pattern of usage to determine truth conditions. (From (c), (d))

This completes the reductio, for (e) is false. No amount of purely syntactical information in the sense at issue is in itself sufficient to determine that there is a rich enough pattern of usage to determine truth conditions. The full story about grammatical categories and constructional proprieties is silent on the crucial facts about usage, and is consistent with their absence. The point is not that

have their semantic properties, and in particular get to have the particular truth conditions that they do have. For that discussion we need the 'physical type' notion of a sentence rather than a notion that presupposes that the question has been answered. 
syntax by itself is consistent with many different hypotheses concerning which truth conditions are possessed. Having a hat is consistent with many different hypotheses concerning which hat one has, but nevertheless having a hat is sufficient for having some particular hat. The point is that syntax by itself is consistent with the absence of something that is necessary for having any truth condition at all, namely, enough by way of usage, and so it takes more than syntax to make for truth aptness. This is why examples of sentences given in logic classes to illustrate, say, existential generalisation - perhaps I write 'Fred has flat feet', or 'Fa', on the board and write under it 'Something has flat feet', or 'ExFx' - are typically not truth apt. For there is not enough context and usage of the right kind to settle on one interpretation rather than any other of the words and symbols. It is not the case that 'Fred has flat feet' is either true or false but I did not tell the students enough for them to work out which it is. Rather, I did not do enough to make it the case that there is an answer for them to be ignorant about.

\section{Disciplined syntacticism and the platitudes about truth aptness}

The obvious response to the argument against syntacticism is to move to disciplined syntacticism. For a sentence to be truth apt it must not only have the syntactic features mentioned, there must also be standards whereby the use of that sentence in a community are judged to be appropriate or inappropriate; in other words, it must be subject to standards of discipline. Only so is the sentence apt to determine one truth condition as opposed to another. The difference between syntacticism and disciplined syntacticism is precisely the addition of facts about usage that the argument against syntacticism showed needed to be included. Here is how Boghossian expresses the view (as applied to aptness for minimal truth) 
... the requirements are that the sentence possess a role within the language: its use must be appropriately disciplined by norms of correct utterance; and that it possess an appropriate syntax: it must admit of coherent embedding within negation, the conditional and other connectives, and within contexts of propositional attitude. 13

Clearly, disciplined syntacticism, like syntacticism, entails that ethical sentences and conditionals are truth apt. If it is true, it affords the quick refutation of non-cognitivism and no-truth theories of conditionals that minimalists seek. For both ethical sentences and conditionals, in addition to meeting the various syntactic criteria, are such that there are firmly acknowledged standards for their proper and improper use among speakers of English. (Some might quarrel with the claim that the standards are firm enough in the ethical case, but we grant the point.)

Our objection to disciplined syntacticism is not to what it says, but to what it fails to say. It does not say enough about a central platitude governing truth aptness and its connection with belief. Wright urges that there is a platitudinous connection between assertion, belief and content:

...assertion has the following analytical tie to belief: if someone makes an assertion, and is supposed sincere, it follows that she has a belief whose content can be captured by means of the sentence used. 14

13 Op. cit., p. 163. The two conditions are first put forward as necessary, and then, on p. 164, argued to be jointly sufficient. Wright's version of disciplined syntacticism is similar, see, e. g., op. cit., p. 74.

14 Wright, op. cit., p.14. 
Our contention is that there is an analytical tie between truth aptness and belief. A sentence counts as truth apt only if it can (barring problems about sentences that are too long to be understood, obvious contradictions, and the like) be used to give the content of a belief, specifically, the belief of someone who asserts the truth apt sentence. Part of the story about rich patterns of usage required to confer truth conditions must be a story about using the sentence to express belief. This is part of the reason why sentences used as examples in logic classes are typically not truth apt. The conventions in play break the tie with belief. The teacher and students alike know, and know that they know, that the sentences being produced are not expressions of belief. The truistic nature of the connection is reflected in the automatic way we use sentences in 'that' clauses to say what we and others believe. And this platitude needs to be included in any account of truth aptness. For when we do conceptual analysis we have to respect platitudinous connections. They are the very stuff that conceptual analyses are made from. In analysing a concept our aim is to capture the network of platitudes that surround that concept and so capture its meaning.

This general idea is familiar, having perhaps been given its clearest expression by David Lewis in his treatment of theoretical terms, and in his subsequent application of the idea to the analysis of mental state terms. 15 And minimalists themselves embrace it. As Wright puts it for the case of truth:

The root idea, I suggest, is that we should not look for more of a truth predicate than its compliance with a certain set of very general, very intuitive principles - indeed, a set of platitudes ... If an interpretation of 'true' satisfies these platitudes, there is, for minimalism, no further

15 David Lewis, 'How to Define Theoretical Terms', reprinted in his Philosophical Papers, Oxford University Press, 1983, Vol. I, pp. 78 - 95. 
metaphysical question whether it captures a concept worth regarding as truth. 16

However, having thus embraced the ideal of deriving analyses from networks of platitudes, Wright himself goes on to suggest that minimalism should 'enshrine satisfaction' not of all the platitudes about truth, but rather, at least 'pro tem', just 'platitudes about assertion and negation'17, platitudes which, in his view, are summed up in the requirements of syntax and discipline. This explains why Wright, while granting the analytic connection with belief, does not explicitly include it in his account of discipline. But given the general method he embraces, this is surely a mistake. The right view is that there is no natural stopping point in analysing a concept short of finding an analysis that captures the whole network of the central, equally appealing platitudes surrounding the concept that we are trying to analyse - provided, of course, that they really are central, and that they can all be satisfied. For to stop short of capturing all of the platitudes is to make an arbitrary distinction between platitudes; it is to decide, for no reason, that certain platitudes are, and certain platitudes are not, central for elucidating the concept that is up for analysis. Our complaint then is that disciplined syntacticism does not include all of the platitudes about truth aptness, and especially does not include the platitude about belief.

We will now see why the platitude about belief matters for the debate over non-cognitivism in ethics and no-truth theories of conditionals. The crucial point will be that a theory of truth aptness that respects all the platitudes, and in particular the platitude connecting truth aptness and content of belief, is not in any real sense minimal. It does not make it 'easy' to be truth apt. Thus it would be beside the point to respond to our objections to disciplined syntacticism by

16 Wright, op. cit., p.34.

17 Op. cit., p. 35. 
supplementing the account of discipline. Some suitably supplemented disciplined syntacticism might be a perfectly acceptable account of truth aptness, but, as we will see, would not then serve to close the debate over the truth aptness of conditionals and ethical sentences.

\section{The non-minimal part of the story about truth aptness}

According to the approach to analysis that sees respecting the platitudes as central, a sentence is truth apt if and only if it has those features that connect platitudinously with having a truth condition. For example, it must have the appropriate syntax, it must be disciplined, it must be possible to use it to give the content of a belief, and so on and so forth. The beauty of this approach to analysis is that it is hard to see how anyone could object to it. An objection to an analysis consists in pointing to something intuitively evident that conflicts with it. But if we have included everything platitudinous, there is no such intuition to be found.

Now, in one sense of the term 'minimal', a platitude-respecting theory of truth aptness is minimal, for it requires us to make no controversial assumptions about what is involved in having a truth condition. However it is not minimal in another sense of the term 'minimal'; for it does not entitle us to the view that whether or not a sentence is truth apt is something that we can decide independently of our metaphysical and theoretical commitments. It is not minimal in the sense in which syntacticism and disciplined syntacticism are.

The reason for this is that it is not a minimal matter whether or not a state is a belief. Hence the platitude connecting truth aptness with belief means that it is not a minimal matter whether or not a sentence is truth apt. It is part of our concept of a belief that we form beliefs, and particularly beliefs about contingent matters of fact, as a result of, inter alia, perceptual interaction with the world. This reflects the more general truism about belief that it is a state 
designed to fit the facts. It is also part of our concept of a belief that it combines with desire to guide us around the world. As the point is often put, our concepts of belief and desire have to be inter-defined. Again, it is part of our concept of a belief that beliefs tend to evolve in a rational manner under the impact of information. What marks off merely putatively informational states from beliefs is inter alia the way beliefs evolve.

This means, as we might put it, that we have to dirty our hands. To show that a sentence is truth apt it is not enough to show that it passes the requirements of syntax and discipline. It needs also to be shown that the state an agent is in when she is disposed to utter a sentence with the appropriate syntax and discipline bears the relations to information, action and rationality required for the state to count as a belief. And this is a substantial matter.

How might the minimal minimalist about truth aptness, the supporter of syntacticism or disciplined syntacticism, reply? She might say that, whether or not the state that a subject is in when she is disposed sincerely to utter a sentence with the appropriate syntax and discipline is a belief in the sense in which we have been using the term 'belief', it is obvious that she does at least have a belief in some minimal sense. 18

In our view there is a confusion in thinking that minimalism about truth supports minimalism about truth aptness via supporting minimalism about belief. To believe something is to believe that it is true. If we are minimalists about truth, then the difference between believing something and believing that it is true is minimal, indeed, non-existent; but that does not mean that believing something is itself, in some sense, minimal. As we see it, it is wrong to suppose that minimalism about truth itself somehow supports or makes coherent a

18 This position has been suggested to us in discussion and correspondence, and is prominent in Horwich, 'The Essence of Expressivism', op. cit. 
minimal conception of belief. The minimal minimalist must therefore tell us in what sense the states she is talking about count as beliefs.

She might reply that they are beliefs in the ordinary sense of the word 'belief' on the ground that in common parlance we describe someone who is disposed sincerely to utter the sentence 'Torture is wrong' as believing that torture is wrong, and similarly we talk of people believing that if it rains the match will be cancelled. She might indeed insist that it is a platitude that there are ethical and conditional beliefs and observe that, in light of this, on the platitude preserving approach to analysis, it follows that there are ethical and conditional beliefs.

But the issue is not one about common parlance, but rather about the centrality of platitudes and their robustness under scrutiny. In common parlance we also apply the words 'true' and 'false' to ethical sentences and to conditionals. This does not mean that we should conclude straight away that given the platitude preserving approach to analysis, ethical and conditional sentences are truth apt. On that approach the issue does not turn on the prevalence of the words 'belief' and 'true' and 'false' in everyday talk about ethics and conditionals. The issue turns rather on the appeal of the claim that ethical sentences and conditionals are truth apt and give the content of beliefs after reflection and explanation of the issues in the light of all the relevant platitudes. After all, the word 'valid' is often enough used to describe statements rather than arguments in everyday talk, and the words 'thinking' and 'memory' are used to describe what is going inside an electronic calculator. But that does not mean that statements are valid and that calculators think and remember, and what reveals this is what we say after considered reflection and explanation of the issues.

What the minimal minimalist thus has to show is that, after due reflection and explanation of the issues, and in light of the central platitudes, we would say that the state that someone is in when she is disposed sincerely to utter a 
sentence with the appropriate syntax and discipline is appropriately called a 'belief'. And in order to do that, she has no choice but to ask whether or not the state that she is in respects the platitudes about beliefs that we have described. Is it a state that is designed to fit the way things are, which guides us in realising our desires, and which tends (tends) to evolve rationally? If the answer is yes, she is granting our point; if the answer is no, we aren't being offered any sense of belief at all. Minimal belief is no more belief than a decoy duck is a duck.

An example helps bring the point out. The head of department thinks that he believes that women are as intelligent as men. It is clear to his colleagues that he does not. It is a case of self-ignorance (but not ,we may suppose, one of inconsistent belief). Nevertheless, he produces the sentence 'Women are the equal of men' on the appropriate occasion; he understands the sentence; he is sincere in some sense or other (he does believe that he believes that women are as intelligent as men); and so on. 19 Why is it obvious to his colleagues that he does not believe that women are the equal of men? Because the states inside him do not play the right functional roles. Situations of this kind are far from unknown and in any case it would be wrong-headed to dismiss them a priori on the basis of minimalism about truth.

\section{The Traditional Debate Vindicated}

We turn finally to the bearing of our discussion of truth aptness on the debate about non-cognitivism in ethics and no-truth theories of conditionals. Our

19 A sincere assertion of 'Women are the equal of men' might be defined as one corresponding to the belief that women are the equal of men, in which case our point should be re-phrased as one about the non-minimal nature of sincere assertion. 
discussion suggests that there are two steps involved in showing that some given class of sentences fails to be truth apt. The first is to advance a plausible necessary condition for a sentence to be truth apt, and this necessary condition must, if we are right, draw on the platitudes. The second is to show that the sentences in question do not satisfy that necessary condition. Now consider the following, already adverted to, platitude about truth aptness:

(5) If $S$ is truth apt then S can give the content of a user's belief

and recall the debates in the ethics and conditionals literatures.

One traditional case for non-cognitivism in ethics rests on a Humean doctrine about belief together with a claim about the relationship between the circumstances in which we produce ethical sentences and motivation. The Humean doctrine is that no belief can have a conceptual connection with motivation. But, runs the argument, the state that we naturally call 'the belief that torture is wrong', the state that leads us to utter the sentence 'Torture is wrong' in the kind of circumstances we might naturally take to make the production count as the expression of belief, does have a conceptual connection with being motivated against torture. Hence, the argument concludes, that state is not a belief. In brief, there is no such thing as the belief that torture is wrong - no such thing as the belief whose content is given by the sentence 'Torture is wrong' - because if there were, it would have a conceptual connection to motivation that no belief can have. 20 But this is precisely an

20 As we understand it, this is the argument that most moves R. M. Hare, see The Language of Morals, Oxford University Press, 1952, esp. Chs. 1 and 2, provided the sentence is being given its primary evaluative meaning. (In Hare's scheme ethical sentences have purely descriptive secondary meanings in addition to their primary meanings, and there will on any reckoning be beliefs 
argument that the necessary condition for truth aptness captured by (5) is violated by 'Torture is wrong'.

Another traditional case for non-cognitivism in ethics derives from our knowledge of the naturalistic or descriptive nature of the conditions that prompt the production of ethical sentences, combined with an argument that no descriptive translation of ethical sentences is possible. Again, this is precisely an argument that the necessary condition for truth aptness captured by (5) is violated by ethical sentences. The state that underlies the production of ethical sentences could only be a belief if its content were descriptive - it is at best the descriptive facts it is trying to fit - and we have, it is argued, a proof that the content could not be descriptive. 21

A similar point applies to the familiar case for no-truth theories of conditionals. This case, recall, is that the state we might naturally call 'the belief that if it rains, the match will be cancelled', the state that leads us to utter the sentence 'If it rains, the match will be cancelled' in the kind of circumstances we might naturally take to make the production count as the expression of belief, corresponds quite generally to the state of giving a high, or high enough in the circumstances, conditional subjective probability to the match being cancelled given it rains. But, runs the argument, there are a number of well-known proofs to the effect that this state can not be the subjective probability of anything -

whose content is given by those secondary meanings.) Simon Blackburn also appeals to this argument in Spreading the Word, Oxford University Press, 1984, pp. 187-9.

21 See A. J. Ayer op. cit. We take it that this is also the argument that most moves Simon Blackburn, see op. cit. pp. 181 - 187, and esp. 'How to be an Ethical Anti-Realist' in Peter A. French, Theodore E. Uehling, Jr. and Howard K. Wettstein (eds) Midwest Studies in Philosophy Volume XII: Realism and AntiRealism, University of Notre Dame Press, 1987, pp. 361-375. 
though it is, of course, a quotient of subjective probabilities. Hence, the argument concludes, that state is not a belief. In brief, there is no such thing as the belief that if $\mathrm{P}$ then $\mathrm{Q}$ because, if there were, its degree would be given quite generally by the subjective probability of $Q$ given $P$, and we can prove that that is impossible. Again, we have an argument that the necessary condition for truth aptness captured in (5) is violated. 22

As it happens, we think that these cases can be defeated. We hold that ethical sentences and conditionals are truth apt. But the crucial point is that they have to be defeated in their own terms. They don't fail in virtue of the true, minimalist doctrine about truth aptness. Reflection on the requirements placed on truth aptness by any plausible minimalism - any minimalism that respects all the platitudes including especially the tie with belief, and not a minimal minimalism - shows that the arguments traditionally offered in the ethics and conditionals literatures address exactly the right questions.

Thus, if the argument that ethical sentences do not give the content of belief fails, it fails either because it is false that the state we might naturally call 'the belief that torture is wrong', the state that leads to the production of that sentence in the appropriate circumstances, is conceptually linked to being motivated to stop torture, or because it is false that there is no necessary connection between belief and motivation. If the argument that conditionals do not give the content of belief fails, it fails either because the proofs that there is nothing whose degree of belief is in general a conditional subjective probability fail, or because the production of 'If $P$ then $Q$ ' is not caused, in the way typical

22 This is the argument that moves Ernest Adams, see, e. g., The Logic of Conditionals, Reidel, 1975. The proof he draws on is due to David Lewis, see, e. g., 'Probabilities of Conditionals and Conditional Probabilities, Philosophical Review, LXXXV, 1976, 297 - 315. Lewis does not, though, draw the no-truth conclusion. 
of manifestation of belief, by the subject's giving a high subjective probability to $\mathrm{Q}$ given $\mathrm{P}$, or because there is some belief state whose degree is not given by the subjective probability of $\mathrm{Q}$ given $\mathrm{P}$, and which, although it does not have the connection to the production of sentences most typical of belief, has a connection near enough for the sentence to count as true if and only if the belief is. 23

\section{Postscript on minimalism about truth}

Our emphasis has been on the distinction between minimalism about truth and minimalism about truth aptness, and how any plausible minimalism about truth aptness vindicates the traditional debates. We have said little, except by way of preliminary setting up of the discussion, about minimalism about truth per se, except that it should be sharply distinguished from minimalism about truth aptness. We conclude by noting a moral for minimalism about truth that arises from our discussion of truth aptness.

23 A story of this last kind is told by Frank Jackson in Conditionals, Basil Blackwell, 1987. The belief with a less than completely typical connection to 'If $\mathrm{P}$ then $\mathrm{Q}^{\prime}$ is the belief that either not-P or $\mathrm{Q}$. Of course, it is a matter of judgement whether a less than completely typical connection between belief state and sentence is nevertheless close enough to the completely typical one to mean that the sentence counts as true iff the belief is. The view that 'If $P$ then

$Q$ ' has the truth conditions of 'P hook Q', and the view that 'If $P$ then $Q$ ' has no truth conditions at all, but has assertion conditions tied to the subjective probability of Q given $\mathrm{P}$ being high enough, are not on this way of looking at matters that different. They are the result in drawing a possibly vague boundary in different places. 
Minimalism about truth is sometimes characterised as the appropriate generalisation of the idea that there is nothing more to 'Snow is white' being true than snow's being white. If this is understood as a doctrine about sentences, it is false. A necessary condition of a sentence being true is that it be truth apt, and we have seen that that involves a great deal more than snow's being white. The rich pattern of usage and convention required to be truth apt goes far beyond snow's being white. 24 Of course, if it is understood as a doctrine about truth of propositions, or of ordered couples of a sentence type and an interpretation, there is no complaint on this score. 25 And, indeed, it is trivial that ethical propositions and interpreted ethical sentences are truth apt. That follows from the meanings of 'proposition' and 'interpretation'. The live issue is whether there are any ethical (or conditional) propositions, or whether ethical (or conditional) sentences have interpretations in the classical sense.

We suspect that a conflation of minimalism about truth as a doctrine about sentences with minimalism about truth as a doctrine about entities that are by definition truth apt underlies the idea that minimalism about truth leads to minimal minimalism about truth aptness. Thus, Boghossian in arguing that minimalists about truth must embrace that version of minimal minimalism about truth aptness we called 'disciplined syntacticism' says

Any proposed requirement on candidacy for truth must be grounded in the preferred account of truth. On the deflationary account of truth, there

24 This is why we disagreed with Field about the plausibility of deflationary truth as he characterised it.

25 Horwich, for instance, as we noted earlier, understands minimalism about truth as primarily a doctrine about truth of propositions, see Truth, op. cit., p. 17. 
is no substantive property - truth - that sentences or thoughts may enjoy... 26

But there is no issue about whether thoughts are candidates for truth, though there may of course be an issue about whether something is a thought. And in the case of sentences there is a substantive property that a sentence may or may not enjoy, that of satisfying the platitudes definitive of truth aptness, including the rich pattern of usage and the connection with belief, and that is a necessary condition for being true. No argument that what divides the true from the false among the truth apt is not the possession of a substantive property can negate the fact that what divides the truth apt from the non-truth apt is a substantive property. 27

Australian National University Monash University

26 Boghossian, op. cit., p. 65.

27 We have been greatly helped by comments from Philip Pettit, Geoff SayreMcCord, Huw Price, John O'Leary-Hawthorne, the Editor, a referee, and, especially, Richard Holton. 